\title{
Article \\ Harm Perception in Response to Pictorial Warning Labels Predict Higher Non-Smoking Intention among Korean Adolescents
}

\author{
Jun Hyun Hwang (1) and Soon-Woo Park * \\ Department of Preventive Medicine, Catholic University of Daegu School of Medicine, Daegu 42472, Korea; \\ pmdr213@cu.ac.kr \\ * Correspondence: parksw@cu.ac.kr; Tel.: +82-53-650-4493; Fax: +82-53-654-3881
}

Citation: Hwang, J.H.; Park, S.-W. Harm Perception in Response to Pictorial Warning Labels Predict Higher Non-Smoking Intention among Korean Adolescents. Int. J. Environ. Res. Public Health 2021, 18, 1404. https://doi.org/10.3390/ ijerph18041404

Received: 31 December 2020

Accepted: 30 January 2021

Published: 3 February 2021

Publisher's Note: MDPI stays neutral with regard to jurisdictional claims in published maps and institutional affiliations.

Copyright: (c) 2021 by the authors. Licensee MDPI, Basel, Switzerland. This article is an open access article distributed under the terms and conditions of the Creative Commons Attribution (CC BY) license (https:/ / creativecommons.org/licenses/by/ $4.0 /)$.

\begin{abstract}
Because of recent controversy surrounding the use of excessively graphic pictorial warning labels (PWL) on cigarette packs in South Korea, it is necessary to provide evidence to evaluate their effectiveness as a tobacco control policy according to the harm perception they evoke. An analysis was performed using a nationally representative survey conducted six months after the introduction of PWLs in South Korea. Among 62,276 survey participants, 43,231 students from grades 7-12 who had seen a PWL in the past 30 days comprised the research sample. Non-smoking intention was evaluated according to the harm perception evoked by PWLs, which predicted higher non-smoking intention among adolescents. Non-smoking intention was particularly higher in daily smokers with harm perception (52.0\%) than those who have never smoked and have no harm perception (40.1\%). In the case of those who perceived harmfulness, non-smoking intention was formed in about $45 \%$ of daily smokers who had no experience of trying to quit in the last 12 months. Therefore, it is important to select PWLs that can arouse in adolescents sufficient harm perception of smoking.
\end{abstract}

Keywords: pictorial warning label; harm perception; non-smoking intention; tobacco control

\section{Introduction}

The well-designed health warning messages on cigarette packs are a key component in comprehensive tobacco control policies that serve as cost-effective measures to raise public awareness on smoking and reduce tobacco use [1]. The use of a pictorial warning label (PWL) is considered more effective than a text-only warning [2]. It was introduced in Canada in 2001 and has since spread worldwide to 100 countries and jurisdictions as of 2016 [3]. The World Health Organization (WHO) Framework Convention on Tobacco Control (FCTC) requires that warning labels including the PWL take up more than 50\% of the cigarette pack's primary display area $[1,4]$.

In several countries, the introduction of the PWL has been delayed for similar reasons. In the case of the United States, tobacco companies argued that the PWL proposed by the Food and Drug Administration (FDA) in 2011 was unduly burdensome and violated the First Amendment, and D.C. Circuit held the FDA rules in 2012 [5]. In Korea, the introduction of the PWL was delayed because it violated the rights of tobacco companies and threatened smokers' rights of happiness [6]. Over 10 years after Korea first made efforts to pursue the bill on PWLs in 2002, it was finally enacted in June 2015 [7]. There was some opposition to the introduction of warning pictures in Korea, prompting the following legal provision to be added [8]: "That the warning pictures shall be based on facts without being overly obnoxious."

According to the Message Impact framework, which proposes the mechanism of the effect of PWLs based on communication and psychological theory, PWLs sequentially affect attention and recall, warning reactions, attitudes and beliefs, intentions, and ultimately, behavior [9]. In a clinical trial on the influencing mechanism of PWLs on smokers' quit attempts, PWLs were proven effective through mediation effects on attention, negative 
effects, social interactions, and thoughts on warnings and the harmful effects of smoking [10]. Other experimental studies supported the differential effects of PWLs according to the level of emotional reactions. In two experimental studies on smokers in the United States, a PWL causing higher negative emotions induced a higher quit intention among smokers [11,12].

Since most of the intermediate factors used in the fore mentioned studies were evaluated using subjective survey items, the effect of PWLs may vary depending on the individual's perception of it. One of the main reasons for the opposition against the introduction of the PWL-that it is unduly burdensome or overly obnoxious-is difficult to objectively evaluate, which challenges the method to increase the PWL's effectiveness. As in the United States and Korea, there is a possibility that the controversy surrounding the selection of PWLs may arise any time in other countries preparing to introduce it or when it comes time to replace them. As a result, it is possible to delay its introduction or even weaken its effects after. As such, subjective perception after exposure to PWL can either act as an obstacle in its introduction or play an important role in maximizing its effect, making the collection of sufficient scientific evidence on it essential. Since the aforementioned studies were only conducted on smokers [11,12], it is necessary to evaluate the effects of PWLs on non-smokers. After the introduction of the PWL in Korea, studies on its effects were conducted, but differences in the effect of individuals' perception by exposure to PWL were not evaluated [13,14].

Our study aims to evaluate the relationship between the level of the harm perception evoked by PWL and non-smoking intention in the general population that includes nonsmokers. For this purpose, we hypothesize that the harm perception in response to PWLs predicts a higher non-smoking intention in the general population of Korean adolescents.

\section{Materials and Methods}

\subsection{Study Sample}

Data from the 13th Korea Youth Risk Behavior Web-Based Survey (KYRBS-XIII) conducted in 2017 by the Korea Centers for Disease Control and Prevention (KCDC) were analyzed for this study. The KYRBS is a nationally representative, self-reported, and anonymous online survey administered to Korean students enrolled in grades 7 to 12 (middle and high school grades). It uses a stratified multistage probability sampling design to produce nationally representative statistics on health behaviors of Korean adolescents. A total of 62,276 students from 799 schools (399 middle schools and 400 high schools) completed the KYRBS-XIII (response rate $=95.8 \%$ ). Of all participants, the study population included those whose responses indicated that they had seen a PWL in the past 30 days ( $\mathrm{N}=43,231,69.4 \%$ of all KYRBS-XIII participants). Participants who were exposed to PWLs were then asked to answer an additional questionnaire to assess their warning reactions to them. Additional details about the sampling method and survey procedure are available elsewhere [15]. The KYRBS was approved by the Institutional Review Board of the KCDC (2014-06EXP-02-P-A).

\subsection{Measures}

For those who were exposed to PWLs, two perceived warning reactions (harm perception, non-smoking intention) were evaluated using the following questions, respectively: (1) "To what extent, if at all, do the warning labels on cigarette packs make you think about the health risks of smoking?", (2) "To what extent, if at all, do the warning labels on cigarette packs make you think about the intention not to smoke?" The possible responses to these questions were: (1) "not at all," (2) "a little," (3) "somewhat," and (4) "a lot." These responses were reclassified into two categories: "yes" for (3) somewhat and (4) a lot; and "no" for (1) not at all and (2) a little.

Other covariates were categorized into two domains: sociodemographic and smokingrelated factors. Sociodemographic variables included sex, grade (7-12), residential area (metropolitan, small- or medium-sized city, or rural), perceived household economic 
status (high, middle, or low), and perceived academic performance (high, middle, or low). Smoking-related factors included participation in smoking prevention education during the last 12 months (yes or no), exposure to anti-tobacco messages in the last 12 months (yes or no), and smoking status (never a smoker, former smoker, and current smoker). Current smoker was further reclassified into three groups: infrequent smoker (1 19 days per month), frequent smoker (20 29 days per month), or daily smoker by frequency of smoking [16].

\subsection{Statistical Analysis}

The weighted percentages of the warning reactions (harm perception of smoking, nonsmoking intention) were calculated. A logistic regression was used to evaluate the factors associated with, and the relationship between, the harm perception of smoking and nonsmoking intention. In the analysis of factors related to non-smoking intention, two models were applied depending on whether harm perception of smoking was included. To evaluate the differential effects of harm perception by smoking status, the odds ratio (OR) for nonsmoking intention was calculated according to the combination of harm perception and smoking status. In addition, non-smoking intention in current smokers can be influenced by their attempts to quit smoking. Therefore, to exclude the effect of quit attempts, a subgroup analysis was conducted on current smokers to examine the effect of harm perception on their non-smoking intention after they were stratified based on experience of trying to quit in the last 12 months. All analyses were performed using the SPSS version 19.0 (IBM, Armonk, NY, USA). A $p$-value $<0.05$ indicates statistical significance. Complex SPSS sampling methods were used to accurately represent Korean adolescents.

\section{Results}

The characteristics of the study participants and their warning reactions to PWLs are shown in Table 1. Of the total participants exposed to PWLs, $83.9 \%$ and $83.1 \%$ had harm perceptions of smoking and non-smoking intention, respectively. The formation of harm perception and non-smoking intention after exposure to PWLs was higher in females, students in the lower grades, and those who participated in smoking prevention education or were exposed to anti-tobacco messages. The maximum gap in harm perception and nonsmoking intention according to smoking status were about $45 \% \mathrm{p}$ and $64.7 \% \mathrm{p}$, respectively, showing a clear dose-response relationship. The formation of non-smoking intention was higher in those who perceived the harmfulness of smoking after exposure to PWLs (93.4\%), than those who did not $(29.5 \%)$.

Table 2 illustrates the factors related to the warning reactions after exposure to PWLs. The logistic regression analysis revealed that females, students from lower grades, those with middle and low perceived academic performance, and those who participated in smoking prevention education or were exposed to anti-tobacco messages, were more likely to perceive the harmfulness of smoking after exposure to PWLs. Similarly, the formation of non-smoking intention after exposure to PWL was also higher in females, students from lower grades, and those who participated in smoking prevention education or exposed to anti-tobacco message. The effect of PWL exposure on warning reactions (harm perception, non-smoking intention) was particularly prominent according to the smoking status with an adjusted OR of 7.10 (95\% confidence interval [CI] 6.33-7.96) and 18.43 (95\% CI 16.34-20.79 in Model 1), respectively. In Model 2, which contains the factor of harm perception, harm perception of smoking had the highest adjusted OR value of 28.38 (95\% CI 26.37-30.53) for non-smoking intention, and the intensity of the relevance of other factors including smoking status became weaker (Table 2). 
Table 1. General characteristics of study population and warning reaction to pictorial warning labels.

\begin{tabular}{|c|c|c|c|}
\hline \multirow{2}{*}{ Characteristics } & \multirow{2}{*}{$\begin{array}{c}\text { All } \\
\left.\text { (Weighted \% }{ }^{\text {a }}\right)\end{array}$} & \multicolumn{2}{|c|}{ Warning Reactions } \\
\hline & & Harm Perception of Smoking & Non-Smoking Intention \\
\hline Respondents (Unweighted N) & 43,231 & & \\
\hline Overall & & 83.9 & 83.1 \\
\hline \multicolumn{4}{|l|}{ Harm perception of smoking } \\
\hline Yes & 83.9 & - & 93.4 \\
\hline No & 16.1 & - & 29.5 \\
\hline \multicolumn{4}{|l|}{ Sex } \\
\hline Male & 50.0 & 81.0 & 79.1 \\
\hline Female & 50.0 & 86.8 & 87.1 \\
\hline \multicolumn{4}{|l|}{ Grades } \\
\hline 7th & 14.9 & 94.3 & 93.7 \\
\hline 8th & 15.4 & 89.2 & 88.6 \\
\hline 9th & 15.0 & 87.0 & 86.2 \\
\hline 10th & 17.3 & 82.1 & 82.0 \\
\hline 11th & 18.8 & 78.7 & 77.8 \\
\hline 12 th & 18.7 & 75.4 & 73.8 \\
\hline \multicolumn{4}{|l|}{ Location } \\
\hline Metropolitan city & 43.5 & 84.4 & 83.6 \\
\hline Small- or medium-sized city & 50.5 & 83.5 & 82.7 \\
\hline Province & 6.0 & 83.0 & 82.4 \\
\hline \multicolumn{4}{|l|}{ Perceived household economic status } \\
\hline High & 39.9 & 84.6 & 83.8 \\
\hline Middle & 45.5 & 84.4 & 83.9 \\
\hline Low & 14.6 & 80.3 & 78.5 \\
\hline \multicolumn{4}{|l|}{ Perceived academic performance } \\
\hline High & 40.3 & 85.0 & 85.2 \\
\hline Middle & 28.4 & 85.1 & 85.0 \\
\hline Low & 31.3 & 81.3 & 78.6 \\
\hline \multicolumn{4}{|l|}{$\begin{array}{l}\text { Participation in smoking prevention } \\
\text { education (last } 12 \text { months) }\end{array}$} \\
\hline Yes & 76.7 & 85.3 & 84.5 \\
\hline No & 23.3 & 79.0 & 78.4 \\
\hline \multicolumn{4}{|l|}{$\begin{array}{l}\text { Exposure to anti-tobacco message } \\
\text { (last } 12 \text { months) }\end{array}$} \\
\hline Yes & 87.8 & 85.3 & 84.4 \\
\hline No & 12.2 & 73.2 & 73.4 \\
\hline \multicolumn{4}{|l|}{ Smoking status } \\
\hline Never smoker & 84.1 & 88.0 & 89.0 \\
\hline Former smoker & 8.0 & 74.8 & 70.7 \\
\hline Infrequent smoker (1 19 days/month $)^{1)}$ & 3.3 & 56.0 & 42.5 \\
\hline Frequent smoker (20 29 days/month) ${ }^{1)}$ & 0.9 & 48.1 & 30.2 \\
\hline Daily smoker 1 ) & 3.8 & 42.7 & 24.3 \\
\hline
\end{tabular}

Data are presented as weighted percentage. a Rows may not be added up to $100 \%$ due to rounding. ${ }^{1)}$ Current smokers.

In each group classified by harm perception of smoking, non-smoking intention was the lowest in daily smokers, and the highest in those who have never smoked, showing a clear dose-response relationship by smoking status (group without harm perception: $3.7 \%$ to $15.24 \%$, group with harm perception: $52.0 \%$ to $95.7 \%$ ). Considering both harm perception and smoking status at the same time, non-smoking intention was higher in the group with harm perception than in the group without; non-smoking intention was higher in daily smokers with harm perception (52.0\%), than those who have never smoked without harm perception (40.1\%). The adjusted OR for non-smoking intention increased significantly with the harm perception of smoking and smoking status (adjusted OR range compared to daily smokers without harm perception: 1.99 [95\% CI 1.10-3.59] to 466.11 [95\% CI 331.75-654.88], p for trend < 0.001), Particularly, the adjusted OR increased sharply among those who perceived the harmfulness of smoking in the same level of smoking status (Table 3). 
Table 2. Evaluation of warning reaction attributed to the exposure to pictorial warning label.

\begin{tabular}{|c|c|c|c|c|c|}
\hline \multirow[b]{2}{*}{ Characteristics $(\mathrm{N}=43,231)$} & \multicolumn{2}{|c|}{ Harm Perception of Smoking } & \multicolumn{3}{|c|}{ Non-Smoking Intention } \\
\hline & $\begin{array}{l}\text { Unadjusted OR } \\
\quad(95 \% \mathrm{CI})\end{array}$ & $\begin{array}{l}\text { Adjusted OR } \\
\quad(95 \% \mathrm{CI})\end{array}$ & $\begin{array}{l}\text { Unadjusted OR } \\
\quad(95 \% \mathrm{CI})\end{array}$ & $\begin{array}{l}\text { Model 1 } \\
\text { Adjusted OR } \\
\text { (95\% CI) }\end{array}$ & $\begin{array}{c}\text { Model } 2 \\
\text { Adjusted OR }^{3)} \\
\text { (95\% CI) }^{3}\end{array}$ \\
\hline \multicolumn{6}{|l|}{ Harm perception of smoking } \\
\hline Yes & - & - & $33.87(31.75-36.14) *$ & - & $28.38(26.37-30.53) *$ \\
\hline No & - & - & Ref & - & Ref \\
\hline \multicolumn{6}{|l|}{ Sex } \\
\hline Male & Ref & Ref & Ref & Ref & Ref \\
\hline Female & $1.54(1.44-1.64) *$ & $1.13(1.06-1.20) *$ & $1.78(1.66-1.90) *$ & $1.18(1.11-1.25)$ * & $1.15(1.06-1.23)$ * \\
\hline \multicolumn{6}{|l|}{ Grades } \\
\hline 7 th & $5.42(4.80-6.13) *$ & $3.50(3.08-3.97) *$ & $5.32(4.72-5.99) *$ & $2.88(2.55-3.26) *$ & $1.73(1.50-1.99) *$ \\
\hline 8 th & $2.71(2.46-2.99) *$ & $1.93(1.74-2.13)$ * & $2.76(2.50-3.04) *$ & $1.77(1.60-1.95) *$ & $1.33(1.18-1.50)$ * \\
\hline 9 th & $2.19(1.99-2.42) *$ & $1.71(1.55-1.89)$ * & $2.22(2.02-2.45) *$ & $1.63(1.48-1.80)$ * & $1.30(1.15-1.47)$ * \\
\hline 10 th & $1.50(1.38-1.63) *$ & $1.30(1.19-1.41) *$ & $1.62(1.49-1.76) *$ & $1.37(1.25-1.50)$ * & $1.26(1.13-1.42)$ * \\
\hline 11 th & $1.21(1.11-1.31) *$ & $1.12(1.02-1.22) *$ & $1.25(1.16-1.34)$ * & $1.16(1.07-1.26)$ * & $1.12(1.02-1.23)$ * \\
\hline 12 th & Ref & Ref & Ref & Ref & Ref \\
\hline \multicolumn{6}{|l|}{ Location } \\
\hline Metropolitan city & $1.10(0.94-1.30)$ & $0.95(0.82-1.10)$ & $1.09(0.93-1.27)$ & $0.88(0.75-1.03)$ & $0.86(0.72-1.02)$ \\
\hline Small- or medium-sized city & $1.03(0.88-1.22)$ & $0.92(0.80-1.07)$ & $1.03(0.88-1.20)$ & $0.880 .75-1.03)$ & $0.88(0.75-1.04)$ \\
\hline Rural & Ref & Ref & Ref & Ref & Ref \\
\hline \multicolumn{6}{|l|}{ Perceived household economic status } \\
\hline High & Ref & Ref & Ref & Ref & Ref \\
\hline Middle & $0.98(0.93-1.04)$ & $1.00(0.94-1.07)$ & $1.01(0.95-1.06)$ & $1.02(0.96-1.09)$ & $1.02(0.95-1.10)$ \\
\hline Low & $0.74(0.69-0.80) *$ & $0.93(0.86-1.02)$ & $0.71(0.66-0.76) *$ & $0.93(0.85-1.01)$ & $0.94(0.85-1.04)$ \\
\hline \multicolumn{6}{|l|}{$\begin{array}{l}\text { Low } \\
\text { Perceived academic performance }\end{array}$} \\
\hline High & Ref & Ref & Ref & Ref & Ref \\
\hline Middle & $1.00(0.94-1.08)$ & $1.17(1.09-1.26) *$ & $0.98(0.92-1.05)$ & $1.16(1.08-1.25) *$ & $1.09(1.00-1.19)$ \\
\hline Low & $0.76(0.72-0.81) *$ & $1.15(1.07-1.23)$ * & $0.64(0.60-0.68)$ * & $1.01(0.94-1.09)$ & $0.90(0.83-0.98)$ * \\
\hline \multicolumn{6}{|l|}{$\begin{array}{l}\text { Participation in smoking prevention } \\
\text { education (last } 12 \text { months) }\end{array}$} \\
\hline Yes & $1.55(1.46-1.64) *$ & $1.30(1.22-1.39) *$ & $1.51(1.42-1.60)$ * & $1.32(1.24-1.41) *$ & $1.21(1.11-1.31) *$ \\
\hline No & Ref & Ref & Ref & Ref & Ref \\
\hline \multicolumn{6}{|l|}{$\begin{array}{l}\text { Exposure to anti-tobacco message } \\
\text { (last } 12 \text { months) }\end{array}$} \\
\hline Yes & $2.13(2.00-2.27) *$ & $1.63(1.52-1.75) *$ & $1.96(1.83-2.10) *$ & $1.43(1.32-1.54) *$ & $1.10(0.99-1.21)$ \\
\hline No & Ref & Ref & Ref & Ref & Ref \\
\hline \multicolumn{6}{|l|}{ Smoking status } \\
\hline Never smoker & $9.87(8.88-10.98) *$ & $7.10(6.33-7.96) *$ & $25.28(22.55-28.35) *$ & $18.43 \underset{*}{(16.34-20.79)}$ & $15.80(13.64-18.30) *$ \\
\hline Former smoker & $3.99(3.51-4.52) *$ & $3.60(3.15-4.10) *$ & $7.51(6.56-8.60) *$ & $6.80(5.91-7.82) *$ & $6.11(5.11-7.31) *$ \\
\hline Infrequent smoker (1 19 days/month) ${ }^{1)}$ & $1.71(1.47-1.99) *$ & $1.47(1.26-1.72) *$ & $2.31(1.96-2.71) *$ & $1.99(1.69-2.34)$ & $1.96(1.59-2.42) *$ \\
\hline Frequent smoker (20 29 days/month) ${ }^{1)}$ & $1.25(0.99-1.57)$ & $1.13(0.89-1.42)$ & $1.35(1.06-1.73) *$ & $1.23(0.96-1.58)$ & $1.20(0.87-1.64)$ \\
\hline Daily smoker ${ }^{1)}$ & Ref & Ref & Ref & Ref & Ref \\
\hline
\end{tabular}

* denoted significant associations $(p<0.05) .{ }^{1)}$ Current smoker. ${ }^{2)}$ Adjusted for sex, grade, location, perceived household economic status, perceived academic performance, participation in smoking prevention education (last 12 months), exposure to anti-tobacco message (last 12 months), and smoking status. ${ }^{3)}$ Additional adjusted for harm perception of smoking to Model 1.

Table 3. Adjusted odds ratios for non-smoking intention caused by the exposure to pictorial warning label according to harm perception of smoking and smoking status.

\begin{tabular}{|c|c|c|c|}
\hline \multirow{2}{*}{\multicolumn{2}{|c|}{ Harm Perception of Smoking $\times$ Smoking Status }} & \multirow{2}{*}{\multicolumn{2}{|c|}{ Non-Smoking Intention }} \\
\hline & & & \\
\hline \multirow{5}{*}{ No } & Daily smoker 2) & 37 & Rof \\
\hline & Frequent smoker (20 29 days/month) ${ }^{2)}$ & 7.3 & $1.99(1.10-3.59) *$ \\
\hline & Infrequent smoker (1 19 days/month) ${ }^{2)}$ & 12.3 & $3.37(2.25-5.04) *$ \\
\hline & Former smoker & 21.0 & $6.50(4.50-9.41) *$ \\
\hline & Never smoker & 40.1 & $15.24(10.93-21.25) *$ \\
\hline \multirow{5}{*}{ Yes } & Daily smoker ${ }^{2)}$ & 52.0 & $28.45(19.95-40.59) *$ \\
\hline & Frequent smoker (20 29 days/month) ${ }^{2)}$ & 54.9 & $30.17(19.68-46.26) *$ \\
\hline & Infrequent smoker (1 9 days/month) ${ }^{2}$ ) & 66.2 & $47.07(32.35-68.49) *$ \\
\hline & Former smoker & 87.4 & $169.16(116.99-244.60) *$ \\
\hline & Never smoker & 95.7 & $466.11(331.75-654.88) *$ \\
\hline & P for trend & & $<0.001$ \\
\hline
\end{tabular}

* denoted significant associations $(p<0.05)$. Those who had experience of exposure to pictorial warning label during the last 30 days $(\mathrm{N}=43,231)$ were analyzed ${ }^{1)}$ Adjusted for sex, grade, location, perceived household economic status, perceived academic performance, participation in smoking prevention education (last 12 months), and exposure to anti-tobacco message (last 12 months). ${ }^{2)}$ Current smoker. 
Table 4 shows the results of analyzing current smokers' non-smoking intention by stratifying the experience of trying to quit smoking during the last 12 months. As with the results including non-smokers in Table 3, in both groups stratified by their experience of trying to quit smoking, the adjusted OR increased according to the combination of harm perception and level of smoking status, having the highest adjusted OR value for nonsmoking intention in those who have never smoked with a harm perception of smoking. Overall, the non-smoking intention was higher in the group that had an experience of trying to quit smoking ( $4.7 \%$ to $69.0 \%)$ than in the group that did not $(1.7 \%$ to $58.8 \%)$, but the increase in adjusted OR value by harm perception after exposure to PWL was steeper in the latter (adjusted OR range compared to daily smoker without harm perception: 4.12 [95\% CI 1.12-15.18] to 90.70 [95\% CI 42.19-195.00] vs. 1.58 [95\% CI 0.81-3.07] to 46.19 [95\% CI 29.82-71.56] in the former group) (Table 4).

Table 4. Adjusted odds ratios for non-smoking intention caused by the exposure to pictorial warning label according to harm perception and smoking frequency stratified by experience of trying to quit smoking among current smokers $(\mathrm{N}=$ 3226).

\begin{tabular}{|c|c|c|c|c|c|}
\hline \multirow{3}{*}{\multicolumn{2}{|c|}{ Harm Perception of Smoking $\times$ Smoking Frequency }} & \multicolumn{4}{|c|}{$\begin{array}{c}\text { Stratification by Experience of Trying to Quit Smoking } \\
\text { during the Last } 12 \text { Months }\end{array}$} \\
\hline & & \multicolumn{2}{|c|}{ No $(N=903)$} & \multicolumn{2}{|c|}{ Yes $(N=2323)$} \\
\hline & & $\underset{\%}{\text { Weighted }}$ & $\begin{array}{l}\text { Adjusted OR }{ }^{1)} \\
\quad(95 \% \mathrm{CI})\end{array}$ & $\underset{\%}{\text { Weighted }}$ & $\begin{array}{l}\text { Adjusted OR }{ }^{1)} \\
\quad(95 \% \mathrm{CI})\end{array}$ \\
\hline \multirow{3}{*}{ No } & Daily smoker ${ }^{2)}$ & 1.7 & Ref & 4.7 & Ref \\
\hline & Frequent smoker (20 29 days/month) ${ }^{2)}$ & 6.9 & $4.12(1.12-15.18) *$ & 7.5 & $1.58(0.81-3.07)$ \\
\hline & Infrequent smoker (1 19 days/month) ${ }^{2)}$ & 9.1 & $5.66(2.47-13.00) *$ & 13.6 & $3.21(2.00-5.17) *$ \\
\hline \multirow{4}{*}{ Yes } & Daily smoker ${ }^{2)}$ & 45.1 & $50.50 \underset{*}{(23.59-108.13)}$ & 54.2 & $24.44(16.09-37.11) *$ \\
\hline & Frequent smoker (20 29 days/month) ${ }^{2)}$ & 43.6 & $52.75 \underset{*}{(18.95-146.89)}$ & 57.1 & $27.66(17.05-44.89) *$ \\
\hline & Infrequent smoker (1 19 days/month) ${ }^{2)}$ & 58.8 & $90.70(\underset{*}{42.19-195.00)}$ & 69.0 & $46.19(29.82-71.56) *$ \\
\hline & $\mathrm{P}$ for trend & \multicolumn{2}{|c|}{$<0.001$} & \multicolumn{2}{|c|}{$<0.001$} \\
\hline
\end{tabular}

* denoted significant associations $(p<0.05) .{ }^{1)}$ Adjusted for sex, grade, location, perceived household economic status, perceived academic performance, participation in smoking prevention education (last 12 months), and exposure to anti-tobacco message (last 12 months). ${ }^{2}$ ) Current smoker.

\section{Discussion}

The effect of PWLs on the formation of non-smoking intention may vary depending on various factors. Among them, harm perception evoked by PWLs has the greatest effect on non-smoking intention among Korean adolescents. This study showed results that are in line with those of previous experimental studies on smokers that indicated how the effect of PWLs was stronger when they evoked more negative emotions [11,12]. Several studies explained this association as a mediation effect of the negative affect evoked by PWLs $[9,10,17]$.

This study went one step further from previous studies and evaluated the effect of harm perception on non-smoking intention according to smoking status. Focusing on the two strongest predictors of non-smoking intention, harm perception evoked by PWLs and smoking status, we identified the possibility that the level of perceived harmfulness of smoking evoked by PWLs could be one of the strategies to maximize its effect. In general, the effect of a PWL is known to be greater in non-smokers than current smokers [9], but we suggest that it can be more effective in smokers than non-smokers according to the perceived harmfulness of smoking it evokes. Additionally, when only evaluating the effect of a PWL on smokers, its harm perception had a great influence on the formation of non-smoking intentions, even in those who had not experienced trying to quit smoking in the last 12 months.

Based on the results of this study, selecting PWLs that raise arousal has the following expected effects. First, a universal effect can be expected among smokers regardless of smoking status or experience of trying to quit. The result of a meta-analysis showed that 
the effect of PWLs was lower in smokers [9], and an experimental study suggested that PWLs had no significant expected effect in regular adolescent smokers [18]. However, considering that non-smoking intention was formed in about $45 \%$ of daily smokers who have not tried to quit, our study supports that PWLs, designed so that the harmfulness of smoking is fully recognizable, may have a universal impact on the majority of people. Second, selecting PWLs that raise arousal can induce a lasting effect because when the effects of a PWL evoke a high emotional response, they can last a long time $[19,20]$. The WHO FCTC recommends the periodic rotation of warning labels as a measure against a wear-out effect over time. However, the rotational period may differ depending on the political situation of implementing the use of PWLs because the WHO's recommended rotation cycle is every 12 to 36 months [1]. Therefore, selecting PWLs that evoke a high emotional response can be a supplemental method to sustain the effect of PWLs for a set period of time.

This research has policy implications for tobacco regulations related to PWLs, and provides evidence which necessitates raising their arousal level. The introduction of PWLs is being opposed because of their inappropriateness, which is unduly burdensome or overly obnoxious. In Korea, these restrictive phrases have been specified in the enactment of the law [8], and the government's initial press release stated that PWLs used in Korea were less graphic than foreign PWLs [21]. However, as shown in this study, since the perceived harmfulness of smoking evoked by PWLs plays a key role in increasing its effectiveness, it is possible to justify selecting PWL types that can maximize its effect through the research results. Moreover, research results show that PWLs that induce low negative emotions are less effective than text-only warning labels [12]. Therefore, it is necessary to strengthen the warning level of PWLs.

Despite low smoking prevalence in adolescents, a total of about $70 \%$ of Korean adolescents were exposed to PWLs [14], and non-smoking intention was formed in about $80 \%$ of them. Adolescents serve as the marketing targets of tobacco companies [22] and are exposed to tobacco advertisements from an early age. Their exposure to these advertisements affects their smoking initiation [23], but strengthening the use of PWLs in terms of harmfulness could lower their intention to start smoking. This association was also supported by a longitudinal study that indicated how negative images on cigarette packs lower the youth's intention to smoke [24]. In this study, the harm perception rate by PWL was higher in students in lower grades. This perceived harmfulness of smoking from an early age leads to the formation of non-smoking intentions, which are attributed to social norms for smoking in adolescents, and can ultimately affect the decrease in smoking prevalence.

The result of this study should be interpreted with caution due to the following limitations. First, unlike experimental studies, the type of PWL or frequency of exposure cannot be controlled. However, this study is based on large-scale nationally representative data with more than 40,000 adolescents at about six months after the introduction of PWLs. Unlike a well-controlled experimental environment, our findings are meaningful because we evaluated the effects under real and complex scenarios, such as the wear-out effect over time caused by long-term exposure. Second, this study used the secondary data of a crosssectional design survey measuring behavioral intention, not actual behavior (non-smokers' intention not to start smoking and smokers' intention to quit). Although it was not possible to evaluate the long-term causal effect of PWLs according to harm perception, it is also meaningful to evaluate intention because it is a key predictor of behavior in both the theory of planned behavior (one of the most used health behavior models) [25], and the tobacco warning model (model explaining the mechanism of PWL) [10]. The long-term harmful effects of smoking evoked by PWLs need to be confirmed through further longitudinal studies. Third, the result should be interpreted with caution since harm perception of smoking may have been sensitized for other reasons (i.e., family history of cancer, etc.), not by PWL. However, this possibility of sensitization by other factors can be minimized because the questionnaire directly asked whether the perception of harm induced by PWL. 
Despite these limitations, this study is insightful as it provides evidence to countries that wish to introduce or strengthen the use of PWLs in terms of their effect on the possibility of reducing smoking prevalence among adolescents. The PWL rotation cycle in Korea is 24 months, and the PWL used in this survey was already updated once, and is about to be updated a second time, but the provisions ("That the warning pictures shall be based on facts without being overly obnoxious.") still remain. Therefore, evidence from these studies can strengthen tobacco control policies related to the packaging of tobacco products.

\section{Conclusions}

Harm perception evoked by PWLs predicts a higher non-smoking intention among adolescents. In particular, in the case of perceiving the harmfulness of smoking after exposure to PWLs, non-smoking intention was formed in about $45 \%$ of daily smokers who had no experience in trying to quit in the last 12 months. Therefore, in introducing PWLs, it is important to select those that can arouse sufficient awareness to increase their effectiveness.

Author Contributions: All authors participated in the interpretation of the results and contributed to the writing of the manuscript. J.H.H. analyzed the data and drafted the manuscript. S.-W.P. designed the study and critically revised the manuscript. All authors have read and agreed to the published version of the manuscript.

Funding: This work was supported by research grants from Daegu Catholic University in 2018.

Institutional Review Board Statement: The KYRBS was approved by the Institutional Review Board of the KCDC (2014-06EXP-02-P-A).

Informed Consent Statement: Participants who were provided with informed consent and agreed to participate in the survey logged in the survey website using the anonymous certification number and participated the survey.

Data Availability Statement: After approval of use, publicly available datasets were analyzed in this study. This data can be found here http:/ / www.kdca.go.kr/yhs/.

Conflicts of Interest: The authors declare no conflict of interest. The funders had no role in the design of the study; in the collection, analyses, or interpretation of data; in the writing of the manuscript, or in the decision to publish the results.

\section{References}

1. World Health Organization. Guidelines for Implementation of Article 11 of the Who Framework Convention on Tobacco Control (Packaging and Labelling of Tobacco Products). Available online: http://www.who.int/fctc/guidelines/article_11.pdf (accessed on 2 February 2020).

2. $\quad$ Brewer, N.T.; Hall, M.G.; Noar, S.M.; Parada, H.; Stein-Seroussi, A.; Bach, L.E.; Hanley, S.; Ribisl, K.M. Effect of pictorial cigarette pack warnings on changes in smoking behavior: A randomized clinical trial. JAMA Intern. Med. 2016, 176, 905-912. [CrossRef] [PubMed]

3. Cigarette Package Health Warnings: International Status Report, 6th edition; Canadian Cancer Society: Toronto, ON, Canada, 2018; Available online: https://www.tobaccofreekids.org/assets/global/pdfs/en/WL_status_report_en.pdf (accessed on 1 March 2020).

4. World Health Organization. Who Framework Convention on Tobacco Control; WHO Document Production Services: Geneva, Switzerland, 2003.

5. R.J. Reynolds Tobacco Co. v. Food \& Drug Admin. Available online: https://casetext.com/case/rj-reynolds-tobacco-co-v-fooddrug-admin (accessed on 1 March 2020).

6. Hwang, J.E.; Cho, S.I.; Lee, S.G. Analysis of the legislative process related to the implementation of graphic health warning labels on tobacco products in south korea. Tob. Induc. Dis. 2020, 18, 03. [CrossRef] [PubMed]

7. Korea Health Promotion Institute; National Tobacco Control Center. Introduction of cigarette pictorial warning label and its meaning. Tob. Free Forum 2016, 10, 2-9.

8. National Health Promotion Act. Article 9-2 (Marking Warning Phrases, etc. On Tobacco). Available online: Https://elaw.Klri.Re. $\mathrm{Kr} /$ kor_service/lawview.Do?Hseq=48657\&lang=eng (accessed on 10 March 2020).

9. Noar, S.M.; Hall, M.G.; Francis, D.B.; Ribisl, K.M.; Pepper, J.K.; Brewer, N.T. Pictorial cigarette pack warnings: A meta-analysis of experimental studies. Tob. Control 2016, 25, 341-354. [CrossRef] [PubMed] 
10. Brewer, N.T.; Parada, H., Jr.; Hall, M.G.; Boynton, M.H.; Noar, S.M.; Ribisl, K.M. Understanding why pictorial cigarette pack warnings increase quit attempts. Ann. Behav. Med. 2019, 53, 232-243. [CrossRef] [PubMed]

11. Li, Y.; Yang, B.; Owusu, D.; Popova, L. Higher negative emotions in response to cigarette pictorial warning labels predict higher quit intentions among smokers. Tob. Control 2020, 29, 496-501. [CrossRef] [PubMed]

12. Evans, A.T.; Peters, E.; Shoben, A.B.; Meilleur, L.R.; Klein, E.G.; Tompkins, M.K.; Romer, D.; Tusler, M. Cigarette graphic warning labels are not created equal: They can increase or decrease smokers' quit intentions relative to text-only warnings. Nicotine Tob. Res. 2017, 19, 1155-1162. [CrossRef] [PubMed]

13. Hwang, J.E.; Cho, S.I. The association between new graphic health warning labels on tobacco products and attitudes toward smoking among south korean adolescents: A national cross-sectional study. BMC Public Health 2020, 20, 748. [CrossRef] [PubMed]

14. Hwang, J.E.; Cho, S.I. The impact of graphic health warning labels on cigarette packs on smoking attitude among korean adolescents. Korean Public Health Res. 2018, 44, 1-15.

15. Kim, Y.; Choi, S.; Chun, C.; Park, S.; Khang, Y.H.; Oh, K. Data resource profile: The korea youth risk behavior web-based survey (kyrbs). Int. J. Epidemiol. 2016, 45, 1076-1076e. [CrossRef] [PubMed]

16. US Department of Health and Human Services. Preventing Tobacco Use among Youth and Young Adults: A Report of the Surgeon General; US Department of Health and Human Services, Centers for Disease Control and Prevention, National Center for Chronic Disease Prevention and Health Promotion, Office on Smoking and Health: Atlanta, GA, USA, 2012.

17. Skurka, C.; Byrne, S.; Davydova, J.; Kemp, D.; Safi, A.G.; Avery, R.J.; Dorf, M.C.; Mathios, A.D.; Niederdeppe, J. Testing competing explanations for graphic warning label effects among adult smokers and non-smoking youth. Soc. Sci. Med. 2018, 211, 294-303. [CrossRef] [PubMed]

18. Moodie, C.; Mackintosh, A.M.; Hastings, G. Adolescents' response to pictorial warnings on the reverse panel of cigarette packs: A repeat cross-sectional study. Tob. Control 2015, 24, e93-e97. [CrossRef] [PubMed]

19. Borland, R.; Wilson, N.; Fong, G.T.; Hammond, D.; Cummings, K.M.; Yong, H.H.; Hosking, W.; Hastings, G.; Thrasher, J.; McNeill, A. Impact of graphic and text warnings on cigarette packs: Findings from four countries over five years. Tob. Control 2009, 18, 358-364. [CrossRef] [PubMed]

20. Peters, E.; Shoots-Reinhard, B.; Evans, A.T.; Shoben, A.; Klein, E.; Tompkins, M.K.; Romer, D.; Tusler, M. Pictorial warning labels and memory for cigarette health-risk information over time. Ann. Behav. Med. 2019, 53, 358-371. [CrossRef] [PubMed]

21. Korea Health Promotion Institute. Introduction of Pictorial Cigarette Pack Warnings Is Effective in Smoking Prevention. Available online: Http:/ / www.Mohw.Go.Kr/react/al/sal0301vw.Jsp?Par_menu_id=04\&menu_id=0403\&page=45\&cont_seq= 340327 (accessed on 2 February 2020).

22. Cummings, K.M.; Morley, C.P.; Horan, J.K.; Steger, C.; Leavell, N.R. Marketing to america's youth: Evidence from corporate documents. Tob. Control 2002, 11 (Suppl. 1), I5-I17. [CrossRef] [PubMed]

23. Lovato, C.; Watts, A.; Stead, L.F. Impact of tobacco advertising and promotion on increasing adolescent smoking behaviours. Cochrane Database Syst. Rev. 2011, 2011, Cd003439. [CrossRef] [PubMed]

24. White, V.; Webster, B.; Wakefield, M. Do graphic health warning labels have an impact on adolescents' smoking-related beliefs and behaviours? Addiction 2008, 103, 1562-1571. [CrossRef] [PubMed]

25. Ajzen, I. The theory of planned behavior. Organ. Behav. Hum. Decis. Process. 1991, 50, 179-211. [CrossRef] 